\title{
Landscape Planning for the Future: Using fossil records to map potential threats, opportunities and likely future developments for biodiversity and ecosystem services
}

Oxford, UK, 9-11 January 2012

Kathy J. Willis' ${ }^{1}$, S. A. Bhagwat ${ }^{2}$ and E. S. Jeffers' 1

'Oxford Long-Term Ecology Laboratory, University of Oxford, UK; Kathy.willis@zoo.ox.ac.uk

${ }^{2}$ School of Geography and the Environment, University of Oxford, UK

T he first meeting of the PAGES Focus 4 Biodiversity Theme was co-sponsored by PAGES and the Oxford Martin School Biodiversity Institute. The overall aim of the meeting was to bring together paleoecologists, modelers and neo-ecologists whose research contributes to understanding the dynamics over time and space of biodiversity and ecosystem services. Forty people attended the meeting representing 14 different countries and five continents.

The three-day meeting was split into seven sessions. The first four focused on the presentation of paleodata relevant to the four key ecosystem services categories (Box 1). Two sessions focused on using the past to assess biodiversity risks in the future, and modeling of long-term data for managing ecosystem services. The final session examined the use of long-term data in ecosystem service valuation and management tools.

Box 1: Ecosystem services are benefits
that people obtain from ecosystems
and are divided into four categories:
- Supporting services
e.g. dispersal of seeds and pollen, cycling
of nutrients, primary production
- Provisioning services
e.g. supply of food, water, pharmaceuti-
cals, energy
- Regulation services
e.g. crop pollination, carbon sequestra-
tion, waste decomposition and detoxifi-
cation
- Cultural Services
e.g. recreational and cultural experienc-
es, scientific discoveries

In addition to the plenary presentations there were also two breakout sessions, which stimulated discussion on (i) the different types of paleoecological

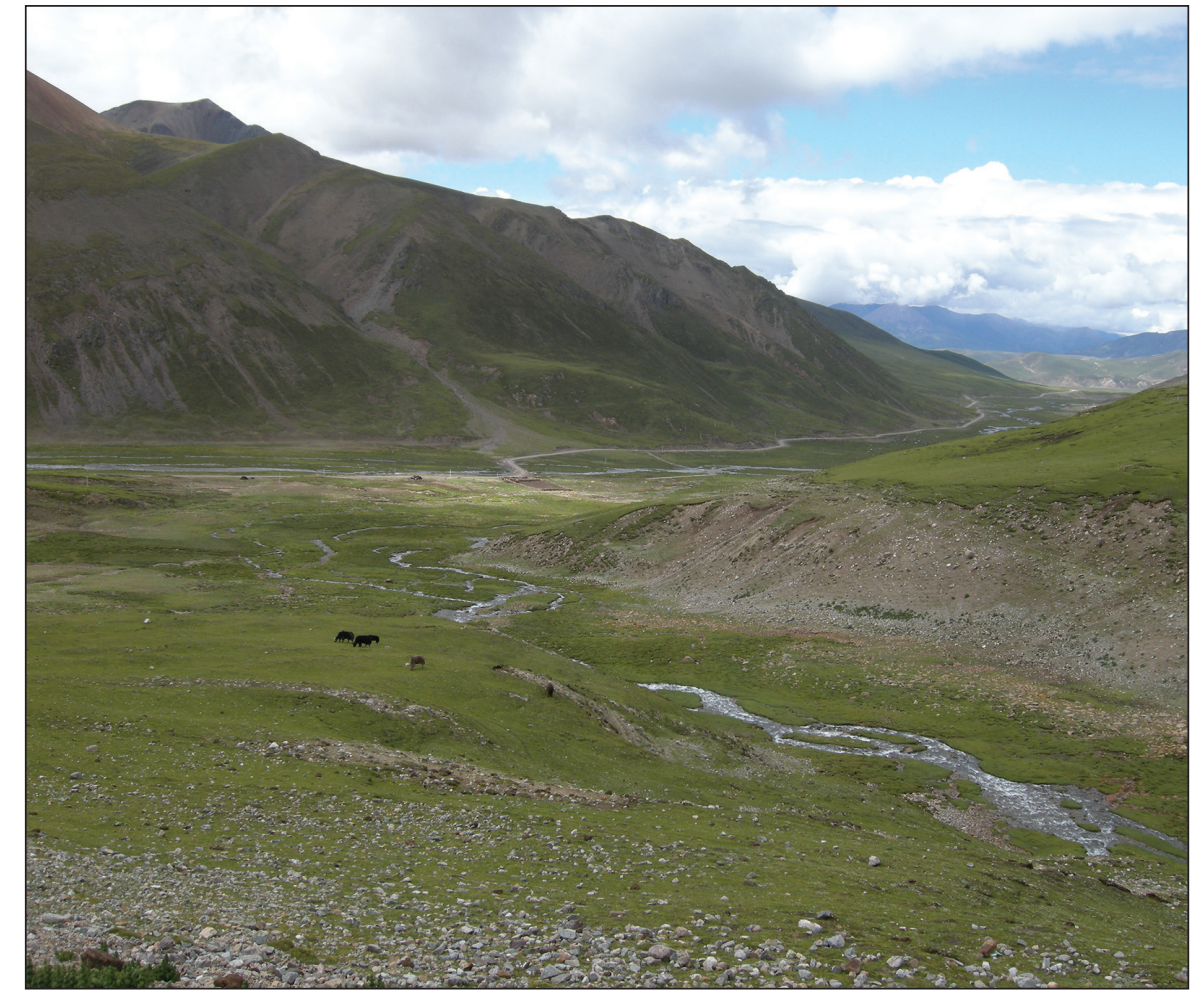

Figure 1: Ecosystems, such as the Tibetan Plateau depicted here, provide a wide variety of ecosystem services such as clean water, recreation space and fodder for grazing. Information on the response of these goods and services to environmental change is recorded in natural archives and is essential for the sustainable management of these resources. Photo: Shonil A. Bhagwat.

data that are relevant to assessing ecosystem services through time and (ii) the databases and sources already available to enable landscape-scale reconstructions, and the identification of data gaps. The overall conclusion from these breakout sessions was that there is already a vast wealth of excellent data and models available for assessing ecosystem function and service provision through time. The major challenge is to determine the appropriate means to disseminate this information to policy makers, habitat managers, and other academics. In particular, the participants discussed the need to devise new methods to present paleodata in a format that is more accessible, possibly through the development of new data management tools and better webportals.
The main outputs of the meeting will be an edited volume in The Holocene entitled Dynamics of Ecosystem Services Through Time: Looking to the Past to Plan for the Future. A policy brief is also in progress to communicate the need for a long-term perspective in national and international ecosystem assessments. Future planned activities of the PAGES Biodiversity Theme include a workshop at the International Ecology Congress (INTECOL) 2013 and a second Working Group meeting in Oxford, UK. The recent establishment of the International Panel on Biodiversity and Ecosystem Services (IPBES) renders this PAGES Theme and its focus on biodiversity and ecosystem services extremely timely. 